\title{
Aspectos bioquímicos do plasma e fluido peritoneal de eqüinos com cólica
}

CORRESPONDENCE TO:

Carlos Augusto Araújo Valadão Departamento de Clínica $e$ Cirurgia Veterinária

Faculdade de Ciências Agrárias e Veterinárias da UNESP

Rodovia Carlos Tonanni, $\mathrm{km} 5$ 14870-000 - Jaboticabal - SP Brasil

\author{
Biochemical aspects of plasma and peritoneal fluid from horses \\ with colic
}

Carlos Augusto Araújo VALADĀo : Orpheu Souza de ÁVILA JÚNIOR; Fugenio de CAMPOS FILHO

\section{RESUMO}

\begin{abstract}
Compararam-se as características do plasma e do fluido peritoneal entre 6 eqüinos clinicamente sadios com as de outros 16 eqüinos com cólica. Encontrou-se uma elevação significante na taxa de proteínas plasmáticas totais e na concentração do fosfato inorgânico nos eqüinos com cólica. Este fato esteve diretamente relacionado a lesōes isquêmicas intestinais. Assim, conclui-se que algumas alterações bioquimicas do plasma e do fluido peritoneal, quando analisadas em conjunto com os dados obtidos no exame clínico, são bons indicadores da severidade do caso.
\end{abstract}

UNITERMOS: Cólica; Peritônio; Fósforo inorgânico; Cavalos.

\section{INTRODUÇÃO}

A etimologia do termo "cólica" refere-se essencialmente à dor intestinal", todavia ele tem sido empregado $\mathrm{cm}$ medicina eqüina para descrever um expressivo estado patológico ou de transtorno orgânico, manifestado por um comportamento estereotipado, indicativo de dor visceral '.

Evidências clínicas mostram que o prognóstico em casos de cólica, em equiinos, tem sido um problema constante e dependente de uma série de fatores, dos quais podem-se destacar a etiologia primária, a duração, a severidade do processo e as complicaçôes endotoxêmicas por absorção de componentes bacterianos ${ }^{7 x}$.

Nos casos de cólical o exame clínico minucioso associado aos laboratoriais, direciona o raciocínio quanto à provável sede do problema. Estes exames fundamentam-se na duração e intensidade dos sintomas; aval iação cardíaca e circulatória perilérical; sondagem estomacal; palpação retal; valores do hematrócito; leucograma; taxa de proteínas plasmáticas totais e, ainda, nos dados bioquímicos e celulares obtidos do fluido peritoneal colhido por paracentese abdominal ${ }^{4}$.

A avaliação do fluido peritoneal tem se mostrado útil na clínica de eqüinos especialmente como método auxiliar de diagnóstico da síndrome cólica '2, pois através da avaliação física (cor e aspecto); bioquímica; classificação e contagem das células ou, pela deteç̧ão de bactérias no fluido, fornece subsídios quanto à integridade da parede intestinal ${ }^{13}$. Assim, a resposta inicial à inflamação ou oclusão vascular é o extravasa- mento de proteínas do plasma para al cavidade peritoneal Com a progressão da lesão ocorre o derrame sanguíneo e migração de leucócitos, elevando tanto o número das células brancas quanto a taxa clas proténas devido ao processo inflat matório intestinal e peritoneal ", indicando desvitalização de alças intestinais. Neste particular, foi observada, após a indução de isquemia intestinal em cães, uma elevação na taxa de fósforo inorgânico no fluido peritoneal ${ }^{10} \mathrm{e}$, posteriormente, foi encontrada uma correlação direta entre a elevação da taxa de fósforo do fluido peritoneal nos casos de cólica em que os animais apresentavam severas lesões na parede intestinal!

Neste estudo objetivou-se correlacional as alterações dos níveis plasmático e peritoneal das proteínas e do fósforo inorgânico com o tipo de alteração e a localização da lesão intestinal de eqüinos com cólica, encaminhados para o tratamento cirúrgico no Hospital Veterinário Governador Laudo Natel da FCA/UNESP - Campus de Jaboticabal.

\section{MATERIAL E MÉTODO}

Foram utilizados 22 equiinos adultos, machos e fêmeas, divididos em grupo controle (GC) composto de 6 animais sadios e grupo experimental (GE) com 16 equiinos com cólica por diferentes etiologias (cólon maior: 3 obstruções, 6 deslocamentos, 1 isquemia; intestino delgado: 1 obstrução, 4 estrangulamentos; 1 tiflite), atendidos e examinados segundo o esquema proposto por Colahan ${ }^{+}$(1985) e que, posteriormente, foram 
VALADÁO. C.A.A.: AVILA JUINIOR. O.S.: CAMPOS FILHO. E. Aspectos bioquímicos do plasma e fluido peritoneal Je eqüinos com cólica. Braz. J. vet. Res. anim. Sci., Säo Páallo. v.3.3. n. $1 .$, p.32-35, 1996 .

submetidos a laparotomia exploratória.

Para colheita do fluido peritoneal, efetuou-se a tricotomia mediana ventral, de $10 \mathrm{~cm} \times 15 \mathrm{~cm}$, seguida da anti-sepsia e, infiltrou-se anestésico local nesse ponto. Na sequiência, com uma lâmina de bisturi procedeu-se a uma pequena incisão na pele, no plano mediano, por onde passou-se, sob pressão, uma cânula mamária de $60 \mathrm{~mm}$ de comprimento, até alcançar a cavidade peritoneal, colhendo-se o fluido peritoneal em frascos estéreis com EDTA. Também colheu-se sangue venoso em frasco com EDTA, por punção da veia jugular, para a análise bioquímica plasmática.

Para a quantificação da proteína tolal e do fósforo inorgânico do plasma e do fluido utilizaram-se, respectivamente, os métodos de Biureto* e de Basques \& Lustosa** enquanto para a dosagem do fibrinogênio empregou-se o método descrito por Foster et al. "( 1975).

Os dados foram analisados estatisticamente pelo teste $t$ de Student em nível de $(p<0.05)$.

\section{RESULTADOS}

Os valores das dosagens bioquímicas de proteína total, fibrinogênio e fósforo inorgânico do plasma e do fluido peritoneal estão agrupados nas Tabs. 1 e 2.

Com relação à análise bioquímica plasmática e peritoneal observou-se uma elevação significante quanto aos valores de proteína total plasmática naqueles animais do GE, em comparação aos do $\mathrm{GC}$, sendo notado que a evolução mais lenta do processo mórbido esteve, na maioria das vezes, relacionada às cólicas envolvendo o cólon maior, principalmente torções, quando os equiinos apresentavam acentuada hemoconcentra ção e perda de proteína para a cavidade, determinando um significante aumento da taxa deste elemento no fluido peritoneal no GE. Quanto à taxa de fibrinogênio, não foi observada alteração significante neste elemento quando se compararam os dois grupos, notando-se que os animais do GE tiveram valor de média superior aos de GC. Neste grupo toi também observado, em alguns animais, a presença de fïbrina na cavidade durante a laparotomia exploratória.

Quanto à análise dos níveis do fósforo inorgânico, foi observado um aumento significante na taxa deste componente no plasma e no fluido peritoneal dos animais do GE, quando comparados àqueles do GC. Naqueles casos de afecções envolvendo o intestino delgado, os níveis desie elemento elevaram-se mais drasticamente tanto no plasma quanto no fluido peritoneal, enquanto nos casos onde existiu comprometimento de porções do cólon esta elevação foi progressiva, porém sempre dependente do tempo de instalação e da gravidade do processo.

\section{DISCUSSĀO}

Na cólica, os fluidos orgânicos alteram-se na dependência do tempo e da localização do processo obstrutivo, sendo mais severos e rápidos os sintomas no comprometimento da porção proximal do intestino delgado. Já as obstruções distais resultam em desidratação e hemoconcentração, por seqüestro de fluido no lúmen intestinal, e os casos de torções e/ou estrangu-

\section{Tabela 1}

Niveis plasmáticos e peritoneal do fósforo inorgânico, proteína total em eqüinos sadios ou com cólica por diferentes etiologias. Estão representadas médias \pm desvio padrão e a faixa de variação entre parênteses. Jaboticabal - SP, 1991.

\begin{tabular}{|c|c|c|c|c|}
\hline \multirow{2}{*}{ Grupos } & \multicolumn{2}{|c|}{ Proteina total (g/dl) } & \multicolumn{2}{|c|}{ Fósforo inorgãnico $(\mathrm{mg} / \mathrm{dl})$} \\
\hline & Plasma & Fluido & Plasma & Fluido \\
\hline Eqüinos sadios & $7.3 \pm 0.6$ & $1.1 \pm 0.4$ & $2.8 \pm 0.6$ & $3.1 \pm 0.3$ \\
\hline$(n=6)$ & $(6.6-8.0)$ & $(0.6-1.7)$ & $(2.0-3.6)$ & $(2,7-3.5)$ \\
\hline Eqüinos c/ cólica & $8.2 \pm 1.3^{*}$ & $4.0 \pm 1.5^{*}$ & $5.0 \pm 1.1^{*}$ & $4.3 \pm 1.2^{*}$ \\
\hline$(n=6)$ & $(5.8-10.0)$ & $(1.2-6.8)$ & $(2.8-6.8)$ & $(2.7-7.3)$ \\
\hline
\end{tabular}

(*) Significaintemente diferente $p<0.05$ 


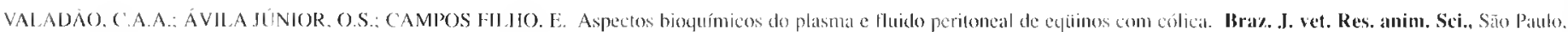
V.3.3. 11.1. . . 32-35. 1996

Tabela 2

Niveis plasmáticos e peritoneal do fósforo inorgânico, proteína total e do fibrinogênio em eqüinos com cólica por diferentes etiologias. Estão representados valores individuais e respectivas médias e desvio padrão por afecção. Jaboticabal - SP, 1991.

\begin{tabular}{|c|c|c|c|c|c|c|c|}
\hline \multirow{2}{*}{ Localização/afecção } & \multirow{2}{*}{ Caso $n^{\circ}$} & \multicolumn{2}{|c|}{$\begin{array}{l}\text { Proteina total } \\
\qquad(\mathrm{g} / \mathrm{dl})\end{array}$} & \multicolumn{2}{|c|}{$\begin{array}{l}\text { Fósforo inorgânico } \\
\text { (mg/dl) }\end{array}$} & \multicolumn{2}{|c|}{$\begin{array}{l}\text { Fibrinogênio } \\
(\mathrm{g} / \mathrm{dl})\end{array}$} \\
\hline & & Plasma & Fluido & Plasma & Fluido & Plasma & Fluido \\
\hline \multicolumn{8}{|l|}{ CÓLON MAIOR } \\
\hline \multirow{7}{*}{ Obstrução } & 1 & 8.2 & 3.4 & 4.8 & 3.4 & 0.5 & 0.2 \\
\hline & 2 & 7.2 & 1.2 & 4.0 & 4.1 & 0.5 & 0 \\
\hline & 3 & 5.8 & 2.1 & 5.7 & 4.7 & 0.4 & 0 \\
\hline & $x \pm s d$ & $7.1 \pm 1.2$ & $2.2 \pm 1.1$ & $4.8 \pm 0.9$ & $4.1 \pm 0.7$ & $0.5 \pm 0.7$ & $0.1 \pm 0.1$ \\
\hline & 1 & 9.4 & 2.2 & 2.8 & 2.9 & 1.0 & 0.1 \\
\hline & 2 & 8.0 & 3.8 & 4.2 & 3.2 & 0.7 & 0.6 \\
\hline & 3 & 5.8 & 5.4 & 3.8 & 3.7 & 0.6 & 0.2 \\
\hline \multirow[t]{4}{*}{ Deslocamento } & 4 & 8.0 & 3.2 & 6.5 & 6.3 & 0.6 & 0.2 \\
\hline & 5 & 9.9 & 4.8 & 5.0 & 4.7 & 0.8 & 0.9 \\
\hline & 6 & 9.0 & 3.2 & 5.4 & 4.7 & 1.1 & 0.2 \\
\hline & $x \pm s d$ & $8.4 \pm 1.5$ & $3.8 \pm 1.2$ & $4.6 \pm 1.3$ & $4.3 \pm 1.3$ & $0.8 \pm 0.2$ & $0.4 \pm 0.3$ \\
\hline Isquemia & 1 & 7.2 & 3.7 & 6.0 & 7.3 & 0.4 & 0.4 \\
\hline \multicolumn{8}{|l|}{ INTESTINO DELGADO } \\
\hline \multirow[t]{4}{*}{ Obstrução } & 1 & 8.4 & 6.8 & 5.4 & 3.7 & 0.4 & 0.2 \\
\hline & 1 & 7.6 & 4.8 & 5.7 & 2.7 & 0.8 & 0.2 \\
\hline & 2 & 10.0 & 5.8 & 5.6 & 4.6 & 0.8 & 0.3 \\
\hline & 3 & 10.0 & 6.1 & 3.3 & 3.4 & 0.4 & 0.2 \\
\hline \multirow{2}{*}{ Estrangulamento } & 4 & 9.4 & 3.5 & 5.1 & 4.7 & 0.9 & 0.1 \\
\hline & $x \pm s d$ & $9.3 \pm 1.1$ & $5.1 \pm 1.2$ & $4.9 \pm 1.1$ & $3.9 \pm 1.0$ & $0.7 \pm 0.2$ & $0.2 \pm 0.1$ \\
\hline \multicolumn{8}{|l|}{ CECO } \\
\hline Inflamação & 1 & 8.0 & 4.5 & 6.8 & 5.2 & 1.2 & 0.3 \\
\hline
\end{tabular}

lamento implicam não somente a distensão e perda de fluidos, mas, também, alterações vasculares que permeiam componentes plasmáticos e, às vezes, bacterianos ${ }^{2}$. Estas observações justificam a elevação na taxa da proteína total do plasma nos equiinos com cólica, notadamente mais pronunciada nos quadros mórbidos que acometeram o intestino grosso nos quais os sintomas da cólica evoluíram, segundo o histórico clínico, de lorma lenta e progressiva. Assim, conseqüentemente as alterações das alças intestinais repercutem nos componentes do fluido peritoneal de acordo com o tempo do processo ${ }^{12}$, sendo as mudanças nos constituintes bioquímicos e celulares do fluido peritoneal uma extensão da lesão entérica. Qualquer condição que comprometa a integridade da parede intestinal pode levar a uma alteração vascular que favoreça o extravasamento de elementos plasmáticos para o referido fluido ${ }^{10.15}$. Desta maneira, justitica-se o significativo aumento na taxa de proteína total contida no fluido peritoneal, neste estudo, onde os valores mais elevados ocorreram nos casos onde as alças afetadas apresentavam baixa perfusão tecidual e comprometimento do retorno venoso ${ }^{12}$.

Os níveis de fïbrinogênio plasmático não sofrem alterações durante as primeiras 24 horas do processo endotoxêmico, pois não existiu ainda perda ou consumo excessivo deste componente no processo de coagulação ${ }^{3}$. Assim, ao analisarem-se os dados referentes a esta fração protéica não observou-se alteração significante em nível plasmático. Todavia, em nível de fluido peritoneal, apesar da ausência de elevação significante. notou-se uma tendência a um aumento na taxa dos animais com cólica e durante o procedimento cirúrgico foi notada, em alguns casos, presença de fibrina na cavidade peritoneal, fato que provavelmente está associado ao consumo deste elemento devido ao processo endotoxêmico secundário à cólica? 
A indução de isquemia intestinal em cães produz uma elevação na taxa do fósforo inorgânico plasmático e do fluido peritoneal, de acordo com o grau de lesão e tempo do processo isquêmico"'. De forma análoga, em equiinos com sintomas de cólica já foi estabelecida uma correlação entre a elevação da taxa do fósforo no fluido peritoneal e a ocorrência de isquemia intestinal, pois este elemento seria permeado, inicialmente, do lúmen para o fluido peritoneal e posteriormente drenado por via linfática para o plasma'. Assim, ao analisar-se o comportamento dos níveis do fósforo no nível plasmático observaram-se, em alguns casos, valores superiores aos determinados no lluido peritoneal, provavelmente devido ao tempo de instalação do processo como já discutido acima. Por sua vez, o aumento na laxa do fósforo no fluido peritoneal talvez tenha ocorrido devido à migração inicial deste elemento para a cavi- dade peritoneal, logo após a ocorrência de lesão isquêmica intestinal ${ }^{1+}$, hipótese esta reforçada pela observação das lesões durante o procedimento cirúrgico, quando se pôde estabelecer uma correlação entre as alterações intestinais e os níveis do fosfato cavitário, conforme já descrito'.

Finalmente, poder-se-ia afirmar que algumas alterações bioquímicas do plasma e do fluido peritoneal, quando analisadas em conjunto com os dados obtidos no exame clínico, são bons indicadores da severidade do caso.

\section{AGRADECIMENTOS}

Ao Prof. Dr. Paulo A. Berlingieri pela colaboração prestada para a realização deste trabalho.

\section{SUMMARY}

Biochemical characteristics of plasma and peritoneal fluid from 6 healthy horses were compared with those from 16 horses with colic. Significant increases were detected in total protein and inorganic phosphorus concentrations in colicky horses. This was particularly true when colic was followed by intestinal ischemia. We conclude that biochemical changes in plasma and peritoneal fluid, when evaluated together with the clinical examination findings, provide a good index of case severity.

UNITERMS: Colic; Peritoneum; Inorganic phosphorus; Horses.

\section{REFERÊNCIAS BIBLIOGRÁFICAS}

I - ARDEN, W.A.; STICK. I.A. Serum and periloneal fluid phosphate concentrations as predictors of major intestinal damage associated with equine colic. Journal of the American Medical Veterinary Association. v.193, n.5, p.927-31. 1988.

2 - BOLTON. J.R.; PASS, D.A. The alimentary tracl. In: ROBINSON. W.F.; HUXTABLE. C.R.R. Clinicopathologic principles for veterinary medicine. New York, Cambridge University Press, 1988, p. 163-93.

3 - BURROWS. G.E. Equine E. coli endotoxemia: Comparison of intravenous and intraperitoneal endotoxin administration. American Journal of Veterinary Research. v.40, p.991-8, 1979

4 - COLAHAN, P.T. Evaluation of horses with colic and the seletion of surgical treatment. Compendium on Continuing Education for the Practicing Veterinarian, v. 7, n. 3, p. 141-9, 1985.

5 - DIETZ, O.: WIESNER, E. Krankheiten des verdanungs apparalos und des biuchlolls. In: DIETZ, O.; WIESSNER, E. Handhuch der pferdekrankheiten fur wisse-schali und praxis. Jena. Gustav Fischer, 1982. v. 3 . chap. 215 , p. 1337

6 - FOSTER, J.B.: De NATALE, A.; DOTTI, L.B. Determinalion of plasma fibrimogen by means of eentrifugation aller heating. In: SCHALM. O.W. JAIN, N.C.: CARROL, E.J. Veterinay hematology, 3.ed, Philadelphii, Lea \& Febiger, 1975, chap.2. p.50.

7-HENRY. M.M.: MOORE. J.N. Equine endoloxemia. In: SMITH. B.P. Large animal internal medicine, Saint Louis, Mosby, 1990, p.668-74.

8-HUSKAMP. B. Ileusdiagnose bleim pferd. Tierarztliche Praxis, v. I. p.67-74, 1973

9-HUTYRA, F.: MAREK, J.; MANNINGER, R.; MOCSY, J. Patología y terapéutica especial de los animales domésticos. 3.ed, Barcelona, L.abor. 1973. p. $186-90$
10-JAMIESON, W.A.: DURAND, D.; WALL, W. Change in serum phosphate levels associated with intestinal infarctation and necrosis. Surgical Gynecology and (Obstetrics, v.140, p. 19-21, 1975.

11-MacKAY, R.J. Endotoxemia. In: ROBINSON. N.E. Current therapy in equine medicine. 3.cd. Philadelphia: W.B. Saunders, 1992. p.225-32

12-PARRY. B.W.: BROWNLOW. M.A. Perioneal l'luid. In; COWELL. R.L.; TYLER. R.D. Cytology and hematology of the horse. Calilornial, American Veterinary Publications, 1992, p.|21-5!.

13-SPIER. S.J.: SNYDER. J.R. Physical and laboratory evaluation of the horso with colic. In: ROBINSON, N.E. Current therapy in equine medicine 3.ed, Philadelphia, W.B. Saunders, 1992, p.193.

14-TAYLOR, B.M.: JAMIESON, W.A.; DURAND, D. Preinlatrction diagnosis of acute mesenteric ischemia by simple measurement of inorganic phosphate in body fluids. Canadian Journal of Surgery, v.22, p.40-5, 1979

15-WILLIANSON, L. Diagnostic procedures for evaluating equine colic. Veterinary Medicine, v.82, n.4, p.401-20, 1987.

Recebido para publicação: 19/07/93 Aprovado para publicaçāo: 13/12/94 